Tinbergen Institute Discussion Paper
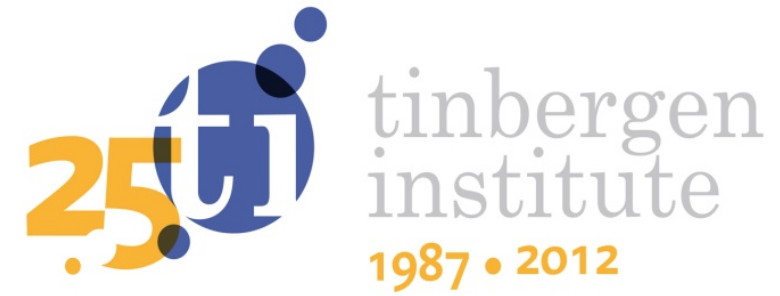

\title{
Savings Adequacy Uncertainty: Driver or Obstacle to Increased Pension Contributions?
}

Ron J.G. van Schie'

Bas Donkers',2

Benedict G.C. Dellaert ${ }^{1}$

' Erasmus School of Economics, Erasmus University Rotterdam;

2 Tinbergen Institute. 
Tinbergen Institute is the graduate school and research institute in economics of Erasmus University Rotterdam, the University of Amsterdam and VU University Amsterdam.

More TI discussion papers can be downloaded at http://www.tinbergen.nl

Tinbergen Institute has two locations:

Tinbergen Institute Amsterdam

Gustav Mahlerplein 117

1082 MS Amsterdam

The Netherlands

Tel.: +31(0)205251600

Tinbergen Institute Rotterdam

Burg. Oudlaan 50

3062 PA Rotterdam

The Netherlands

Tel.: +31(0)10 4088900

Fax: $+31(0) 104089031$

Duisenberg school of finance is a collaboration of the Dutch financial sector and universities, with the ambition to support innovative research and offer top quality academic education in core areas of finance.

DSF research papers can be downloaded at: http://www.dsf.nl/

Duisenberg school of finance

Gustav Mahlerplein 117

1082 MS Amsterdam

The Netherlands

Tel.: +31(0)20 5258579 


\title{
Savings Adequacy Uncertainty: Driver or Obstacle to Increased
}

\section{Pension Contributions?}

\author{
Ron J. G. van Schie ${ }^{1}$ \\ Department of Business Economics, Erasmus School of Economics, Erasmus University \\ PO Box 1738, 3000 DR, Rotterdam, The Netherlands \\ E-mail: vanschie@ese.eur.nl \\ Phone: + 31104081314 \\ Fax: +31 104089169 \\ Bas Donkers \\ Department of Business Economics, Erasmus School of Economics, Erasmus University \\ and Tinbergen Institute, Erasmus University \\ PO Box 1738, 3000 DR, Rotterdam, The Netherlands \\ E-mail: donkers@ese.eur.nl \\ Benedict G. C. Dellaert \\ Department of Business Economics, Erasmus School of Economics, Erasmus University \\ PO Box 1738, 3000 DR, Rotterdam, The Netherlands \\ E-mail: dellaert@ese.eur.nl
}

March 2012

\section{Financial support and acknowledgements:}

The authors wish to thank Netspar for financial support and CentERdata for their available data and assistance in data collection. Netspar had no involvement with the conduct of the research or preparation of the article. We also thank Arvid Hoffman, Carlos Lourenço, and Leo Paas for valuable suggestions on an earlier draft.

${ }^{1}$ Corresponding author 


\title{
Savings Adequacy Uncertainty: Driver or Obstacle to Increased Pension Contributions?
}

\author{
March 2012
}

\begin{abstract}
Deciding how much to save for retirement is a difficult task that includes many uncertainties. In this paper, we use data from a representative Dutch household panel to study the impact of uncertainty regarding one's savings adequacy on retirement savings contributions and information search processes. We combine ideas from the literature in psychology and economics that provide opposing predictions regarding the impact of uncertainty on retirement savings contributions. Our results indicate that the effect of uncertainty is moderated by two factors: an individual's perceived adequacy of current savings and that individual's financial constraints. In particular, we find that uncertainty increases retirement contributions for those who believe that they save adequately; however, it hinders retirement contributions for those who believe that they save inadequately. This effect of uncertainty is further moderated by the availability of financial means: a reduction in uncertainty results in greater contributions to savings only when financial constraints are absent. We also find that uncertainty has both indirect and direct effects on savings information search. In particular, uncertainty indirectly affects savings information search because it impacts individuals' intentions to save, which consequently forces individuals to engage in purchase-oriented information search; however, uncertainty also has a direct effect because individuals engage in ongoing information search processes to directly reduce uncertainty. The implications of these findings are discussed.
\end{abstract}

Keywords: uncertainty, savings adequacy, retirement, financial decision making 


\section{Introduction}

In recent years, individuals in many developed economies around the world have become increasingly responsible for their retirement savings. As a result of a shift from defined benefit to defined contribution pension plans, for example, individuals now confront a wide array of savings decisions (e.g., Lusardi \& Mitchell, 2007a). By now, it is well recognized that individuals are very passive in making these decisions (Choi, Laibson, Madrian, \& Metrick, 2002). As a consequence, there is a clear need for increased saving activities for retirement. For example, almost half of the American working population is not confident that they will be able to live comfortably after retirement (Helman, Copeland, \& VanDerhei, 2010). Similarly, in the Netherlands, many workers believe that future pension income alone will not be sufficient to make ends meet (AFM, 2011). However, attempts to stimulate retirement saving behavior by entities such as policy makers or companies selling retirement savings products are hampered by the same passive attitude that causes the saving problem. In particular, individuals who do not actively think about their retirement savings cannot be effectively advised regarding their need for additional savings and the products that match their specific requirements. Given the importance of increased retirement savings, there is a surprising lack of research that addresses the processes underlying individuals' tendencies to start additional savings contributions (Croy, Gerrans, \& Speelman, 2010; Hershey, Jacobs-Lawson, McArdle, \& Hamagami, 2007).

A rational individual should start saving more when current savings are inadequate to provide financial support during retirement. However, evaluating whether current savings are adequate is a daunting task that involves a complex and ongoing process of forecasting future needs and resources. Recent research has acknowledged the role of subjective uncertainty in explaining behavior in such complex situations (for a review, see Osman, 2010). Although we 
expect that individuals have some notion regarding the adequacy of their current retirement savings, the feeling of uncertainty surrounding their expectations is also likely to affect their saving behaviors. From a theoretical perspective, however, there are no clear predictions regarding the effects of uncertainty on saving behaviors. Our main objective, therefore, is to investigate subjective uncertainty (towards savings adequacy) as a potentially important driver for individuals to save more and to search for retirement savings information (e.g., Lipshitz \& Strauss, 1997). In accordance with Osman (2010), we define savings adequacy uncertainty as one's subjective confidence in predicting whether current retirement savings are adequate or not.

Our first contribution is that we combine insights from psychology and economics that address the behavioral responses to savings adequacy uncertainty. This issue is of particular interest, as research in psychology and in economics has generated opposing predictions regarding the impact of uncertainty on retirement savings contributions, which suggests that the impact of uncertainty operates through two different mechanisms. First, the psychological literature on choice deferral predicts a negative effect on savings contributions because individuals respond to uncertainty by postponing decisions. Individuals tend to put off making decisions to a greater extent as the complexity of the decision task increases (Iyengar, Huberman, \& Jiang, 2004; Tversky \& Shafir, 1992). By contrast, the economic literature on precautionary saving predicts a positive effect from greater uncertainty. The assumption underlying this theory is that individuals cope with uncertainty by increasing the level of wealth accumulation to buffer against unexpected future decreases in income or increases in expenses (Carroll \& Kimball, 2008; Hubbard, Skinner, \& Zeldes, 1995; Lusardi, 1997).

We propose that the effect of savings adequacy uncertainty is moderated by perceived savings adequacy, defined as an individual's expectations of whether current retirement savings 
are adequate or inadequate for a comfortable retirement. In line with the psychological literature, we expect that savings adequacy uncertainty decreases savings contributions for those who think they save inadequately, as uncertainty results in a less compelling incentive to change behavior. However, in accordance with previous literature regarding precautionary saving, uncertainty is predicted to increase savings contributions for those who think they save adequately, and thus should ordinarily have no incentive to begin additional saving behaviors.

Second, we introduce financial constraints as another potential moderator for the effect of savings adequacy uncertainty on individuals' retirement savings contributions. Financial constraints refer to an individual's financial ability to make additional savings contributions. Such constraints may deter individuals from making additional savings contributions simply because there are no financial means to take action. To examine this additional moderating effect, we analyze the three-way interaction among savings adequacy uncertainty, perceived savings adequacy and financial constraints.

Finally, we examine the effect of savings adequacy uncertainty on retirement savings information search. We distinguish between search behavior that is related to making additional savings contributions and unrelated search behavior. The goal of this analysis is to better understand whether information search is only motivated by the specific decision-making process required to support additional savings contributions (e.g., Punj \& Staelin, 1983), or if information search also results from a need to directly cope with uncertainty without a purchase decision in mind (e.g., Bloch, Sherrell, \& Ridgway, 1986).

This paper's findings also have important policy implications. In particular, we provide valuable insights regarding individuals who are at risk of not preparing adequately for retirement. Although a substantial proportion of individuals in this group would benefit from reading more 
retirement savings information because it might reduce uncertainty and hence induce them to start saving more, our results suggest that merely passively providing them with information may not be very effective, simply because these individuals are not very likely to look at that information themselves. Hence, an active approach is needed to inform and motivate such individuals to adequately prepare for retirement.

\section{Retirement savings decisions}

In this section, we develop a conceptual model, summarized in Figure 1, that explains individuals' intentions to make retirement savings decisions. A distinction is made between two important stages in this process, namely, the decision to start saving (or save more) for retirement and the decision to search for retirement savings information. We focus on three important drivers of retirement saving behavior: perceived savings adequacy, savings adequacy uncertainty and financial constraints. The core question addressed by this research is the role uncertainty plays in the retirement savings decision process, as there exist opposing predictions for its consequences.

Figure 1: A conceptual model of individuals' intentions to make retirement savings

\section{decisions}

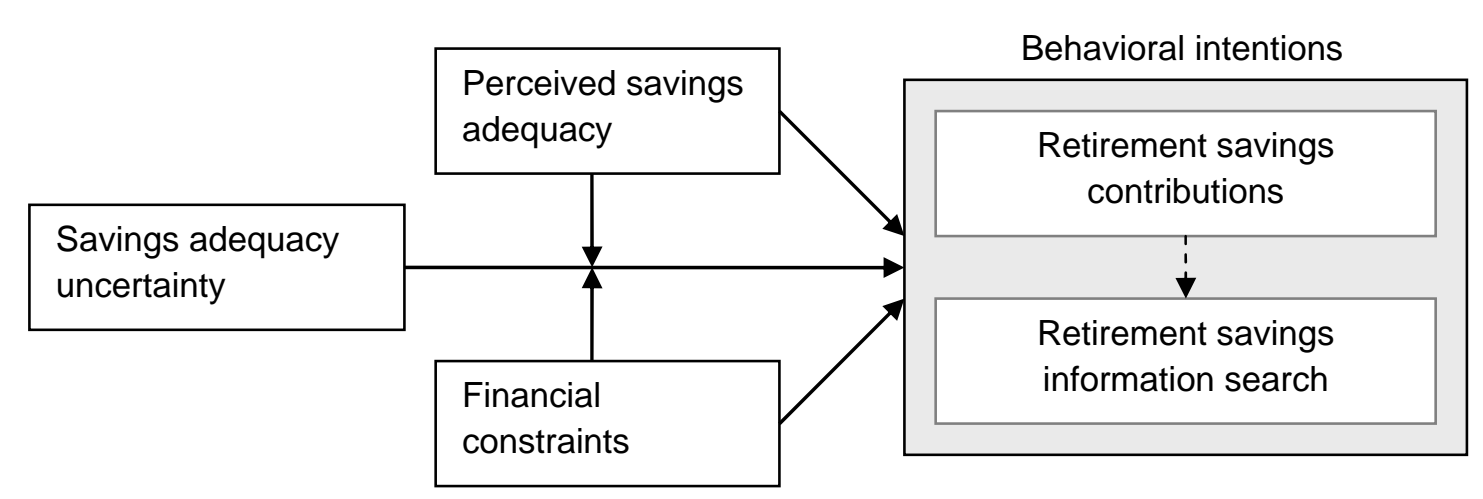

\subsection{Retirement savings contributions}


In this study, we analyze individuals' intentions to make additional savings contributions during the next 12 months. A first step in shaping these intentions is to actively decide on one's pension savings requirements. This step is crucial, as individuals often postpone such complex decisions (Dhar, 1997). Indeed, Choi, Laibson, Madrian, and Metrick (2002), among others, have shown that individuals are not very eager to take active responsibility for increasing their retirement savings. This is reflected by the fact that individuals are heavily influenced by the proposed retirement default option, which implicitly lets others make retirement-related financial decisions for them. In particular, participation rates in default retirement plans appear to be substantially higher under automatic enrollment, and once participants enroll, they make few active changes to the default savings rate and conservative investment choices that are set for them (Beshears, Choi, Laibson, \& Madrian, 2008; Choi et al., 2002; Madrian \& Shea, 2001). Despite this evidence of a passive approach to retirement preparation, the conditions that lead individuals to take more active control over their retirement savings remain poorly understood. Thus, there is still a clear need for individuals to take a more active saving approach. For example, more than $40 \%$ of the American working population (36-62 years) may be at risk of not having adequate retirement resources to meet either basic retirement expenditures or uninsured health care costs (VanDerhei \& Copeland, 2010).

In the Netherlands, unlike in the U.S., a host of saving responsibilities for retirement are performed and organized at a collective level. Sources such as Van Rooij, Lusardi, and Alessie (2011) and Hershey, Henkens, and Van Dalen (2007) provide extensive descriptions of these collective responsibilities. In particular, in addition to a pay-as-you-go public pension scheme (AOW), more than $90 \%$ of Dutch employees are covered by mandatory pension saving plans. However, for many different reasons, e.g., periods of unemployment or self-employment, job 
changes, or uncertainty surrounding the indexation and adjustments of DB pensions, a large number of Dutch workers are at risk of not preparing adequately for retirement (Van Rooij et al., 2011). In fact, only $31 \%$ of Dutch workers are confident that they will not have to set aside their own additional savings to ensure that their gross income after retirement will be sufficient for their needs, whereas more than $20 \%$ of these workers expect that they will need to cut expenses after retirement (AFM, 2011).

\subsection{Retirement savings information search}

Once individuals have recognized that they need to save more for retirement, they will need to gather information to learn more about savings products and retirement planning, as many individuals lack the necessary information to adequately support a savings decision. For instance, almost half of the Dutch non-retired population (18-64 years) has never considered their income and expenses after retirement (Wijzer in Geldzaken, 2011). Similarly, only 46\% of American workers have calculated how much they will need to save for retirement. However, those workers who did calculate this total are more confident that they will be able to accumulate the amount they need for retirement (Helman et al., 2010). The search for more information regarding retirement is therefore an important factor impacting improved retirement saving behavior and an integral part of consumer decision making (e.g., Howard \& Sheth, 1969).

In this study, we focus on individuals' intentions to acquire information regarding pension planning. Individuals may acquire retirement savings information for several reasons. Certain individuals might search for specific product-related information because they intend to adjust their current savings levels. For example, to make a well-informed saving decision, an individual may need to collect information regarding which financial products fit his requirements or provide relevant tax benefits. Other individuals might not be considering specific changes in 
their saving practices, but might simply be looking for more general information addressing topics such as how to establish their desired savings level or increase their retirement knowledge.

Existing information acquisition research has mainly focused on the former situation, in which consumers search for information with a specific purchase goal in mind, i.e., they know what product they want (Beatty \& Smith, 1987; Moorthy, Ratchford, \& Talukdar, 1997; Urbany, Dickson, \& Wilkie, 1989). This type of search behavior has been referred to as goal-directed search. The other scenario, in which individuals acquire information when no specific purchase is considered, is referred to as ongoing search (Bloch et al., 1986; Janiszewski, 1998; Moe, 2003). The latter search type is particularly relevant given that savings goals for retirement are often not particularly well defined, and the environment in which savings decisions are made is subject to continuous change. For example, in many European countries, the question of whether the eligible retirement age should be raised frequently arises (Business Week, 2010). As a response, individuals might engage in ongoing information search to stay informed about these potential changes, without directly considering the adjustment of their current retirement savings.

Until now, little has been known about factors that differentiate individuals who search for retirement information from those who do not, let alone the factors that affect either goaldirected or ongoing retirement information search. We study the role of uncertainty in retirement savings information search, where we differentiate between its impact on goal-directed search behavior that is related to the decision to save more (i.e., purchase-oriented retirement information search) and search behavior that is unrelated to additional savings (i.e., ongoing retirement information search). Hence, we examine whether uncertainty has a direct effect on information search or only affects information search indirectly because of its effect on the decision to make extra savings contributions. 


\subsection{Perceived savings adequacy}

The first driver of retirement saving behavior in our conceptual model is the perceived adequacy of individuals' current savings levels. The adequacy of individuals' retirement savings has received considerable attention (e.g., Scholz, Seshadri, \& Khitatrakun, 2006; Skinner, 2007), and, although the views of savings adequacy expressed in published studies are widely divergent, there is general consensus that at least some households are saving for retirement in a suboptimal manner. More surprising is the finding that individuals are generally aware that their retirement saving behavior is not optimal (Clark, d'Ambrosio, McDermed, \& Sawant, 2004). For example, Choi et al. (2002) observe that two-thirds of employees at a large U.S. food corporation report that their current retirement savings rate is "too low" relative to their ideal savings rate. Of those respondents who indicated that their savings rate is too low, only a small fraction actually increased their savings contribution rate in the subsequent few months. Thus, an important question is why simply being aware of inadequate retirement savings is not always sufficient to induce additional retirement saving behavior.

\subsection{Savings adequacy uncertainty}

One reason why an anticipated lack of sufficient savings for retirement is not acted upon by increasing saving activities is the uncertainty surrounding the perceived savings adequacy. In accordance with Osman (2010), we define uncertainty as individuals' subjective confidence in their prediction of whether they save enough for retirement or not. Previous research has shown that many individuals are poor at estimating the balance between financial needs and financial resources during their retirement years (e.g., Hershey, Walsh, Brougham, Carter, \& Farrel, 1998). Thus, one would expect that individuals perceive substantial uncertainty when deciding how much to save for a comfortable retirement. The effect of uncertainty on retirement saving 
behavior, however, is not unequivocal, as uncertainty may either positively or negatively affect retirement savings decisions, according to different theories in psychology and economics.

First, the psychology literature indicates that individuals might postpone decisions in response to uncertainty. Lipshitz and Strauss (1997) describe uncertainty in the context of action as a sense of doubt that blocks or delays action. This definition is consistent with empirical studies of choice deferral in psychology and marketing. For example, Dhar (1997), Luce (1998) and Tversky and Shafir (1992) demonstrate that individuals are more inclined to postpone their product choice in complex decisions. In an analysis of the decision processes that lead to this deferral behavior, Dhar (1997) shows that individuals who expressed a greater number of thoughts or had relatively equal numbers of favorable evaluations regarding several different options, and therefore presumably faced greater preference uncertainty in the choice task, were more likely to defer their decision. These findings are consistent with a systematic bias toward indecision in retirement decision making (e.g., Madrian \& Shea, 2001; Choi et al., 2002).

By contrast, whereas the psychology literature predicts less action under uncertainty, the literature in economics suggests that uncertainty results in more action, which in this case would constitute additional retirement saving behaviors. In fact, precautionary saving, defined as the additional saving resulting from the knowledge that the future is uncertain, is considered to be one of the most important motives to save, as discussed by Carroll and Kimball (2008) in a recent review. Most research in the precautionary saving literature has focused on the relationship between earnings uncertainty and wealth accumulation (e.g., Carroll \& Samwick, 1998; Lusardi, 1997). In general, these studies find that individuals increase the accumulation of wealth as a type of self-insurance against adverse income shocks. In addition to income uncertainty, other risk factors, such as lifespan uncertainty, health uncertainty, and uncertainty 
about medical expenses, are important precautionary motives as well (Davies, 1981; Hubbard et al., 1995; Palumbo, 1999). Taken as a whole, precautionary saving theory posits that individuals create a savings buffer to remain in sound financial situations in the future, even if they are subjected to unexpected negative changes in income or expenditures.

Because psychology and economics predict opposing effects of uncertainty, we consider the circumstances under which choice deferral is more (vs. less) influential than precautionary savings as a driver of savings intentions. First, we consider individuals who believe that they save inadequately, and hence should have a rather concrete reason to increase savings. These individuals should (rationally) perceive a strong incentive to start saving extra. However, when uncertainty is high, the fact that an individual is at risk of saving inadequately might not be part of that individual's direct experience (Wakslak, Trope, Liberman, \& Alony, 2006). As a consequence, for those who think they save inadequately, a higher level of uncertainty results in less clear preferences for the decision of whether to increase savings for retirement, resulting in choice deferral and a lower intention to start additional savings. By contrast, when individuals believe that they save adequately and hence have no concrete reason to increase savings, but they feel uncertain about this belief, they are likely to engage in (precautionary) saving to reassure themselves that they indeed do save enough for retirement. In summary, the net effect of uncertainty on savings intentions will be increasing with the level of perceived savings adequacy.

We formulate two expectations concerning the effect of uncertainty on information search. First, when individuals have decided to start saving more, they should search for purchaseoriented information to make a proper choice. Therefore, we expect that uncertainty has an indirect effect on information search through its impact on savings intentions. Second, we expect that uncertainty has a direct effect on information search that is unrelated to the decision to save 
more. Even when individuals do not consider adjusting their retirement savings, they may still use ongoing information search to directly cope with uncertainty, such as uncertainties about future pension benefits and requirements. Indeed, behavioral decision theories indicate that information search can be a very relevant strategy to directly reduce uncertainty (e.g., Lipshitz \& Strauss, 1997).

\subsection{Financial Constraints}

The relationship between savings adequacy uncertainty and retirement savings decisions will be further affected by an individual's financial ability to increase contributions. In particular, a lack of available financial resources can act as a constraint when planning for retirement (e.g., Bernheim \& Scholz, 1993; Lusardi \& Mitchell, 2007b). It has been demonstrated, for example, that individuals with the lowest income are at the highest risk of running short of money in retirement (VanDerhei \& Copeland, 2010). In our study, we do not focus on income per se, but rather on an individual's financial ability to change his savings level, which is based on his projected expenditures and income for the next year. Although some individuals might perceive their current pension savings as inadequate and hence feel an urge to better prepare for retirement, they might simply not be able to make additional savings contributions. Therefore, we expect that the interaction effect of uncertainty and perceived savings adequacy is conditional on individuals' financial abilities. In particular, for those who believe they save inadequately, a reduction in uncertainty should result in a greater intention to create additional retirement savings only when financial constraints are absent. Therefore, we expect that there will be a negative three-way interaction effect among savings adequacy uncertainty, perceived inadequate savings, and the absence of financial constraints on savings intention. 


\subsection{Control variables}

Retirement saving tendencies are heterogeneous among individuals. Previous evidence demonstrates that individuals' variance in retirement planning and savings decisions can be partly explained by their socio-demographic and psychological characteristics (e.g., Hershey, Jacobs-Lawson, McArdle, \& Hamagami, 2007). Given these results from the extant research, we include financial literacy, retirement goal clarity, and retirement income knowledge as control variables for this investigation.

Financial literacy - Lusardi and Mitchell (2007b) suggest that simply planning for retirement has a significant effect on savings. Insufficient financial knowledge is one important reason why many people may not plan. In fact, Lusardi and Mitchell (2007b) demonstrate that financial literacy influences planning tendencies and that planning, in turn, increases wealth accumulation.

Goal clarity - Several studies demonstrate that having clear goals for retirement is a significant predictor for retirement planning activities and saving tendencies (e.g., Hershey, Henkens, \& Van Dalen, 2007; Hershey, Jacobs-Lawson, McArdle, \& Hamagami, 2007). Longterm goals serve to specify a behavioral plan that ultimately leads to goal fulfillment (e.g., Beach \& Mitchell, 1987). Hence, the more concrete an individual's concept of retirement is, the easier it will be for that individual to save.

Retirement income knowledge - Empirical evidence is growing that individuals' knowledge of future retirement benefits affects their retirement decision making. Recent work by Chan and Stevens (2008), for example, demonstrates that individuals who are well informed about their pensions are far more responsive to pension incentives than the average individual. 
Other controls - We also control for risk aversion, past information search activities, and previous savings, as past behavior is often an important predictor of behavioral intentions (e.g., Bagozzi \& Dabholkar, 1994). Furthermore, we include a wide set of socioeconomic and demographic control variables.

\section{Data and methodology}

\subsection{Measurement}

\subsubsection{Additional savings and information search intention}

For the two dependent variables, we measure individuals' intentions to make additional savings contributions and their intentions to search for retirement savings information in the next 12 months. We asked individuals, "In the next 12 months, do you expect to make extra contributions in order to supplement your income after retirement?" The answers were measured on a seven-point scale, ranging from "certainly not" to "certainly", and used as indications of intended additional savings. Intentions to conduct information search were measured on a fivepoint scale ranging from "disagree" to "agree" in response to the following two statements: "In the next 12 months I expect to calculate how much money I need to save to retire comfortably", and "In the next 12 months I expect to collect information about financial planning and pensions". These metrics were based on the retirement planning scale of Hershey, Henkens, and Van Dalen (2007). The data obtained from responses to these two statements prove to be reliable (Cronbach's alpha $=0.91$ ), and we use the average score to form the composite information search intention scale.

We measure intentions because in mainstream psychological models, the likelihood that an individual performs a particular behavior is an increasing function of the strength of his intention 
to engage in that behavior (e.g., Ajzen, 1991). A host of previous research, by contrast, has focused on past retirement saving behavior (e.g., total accumulated wealth). However, we cannot use measures of past saving behavior in this research, as our objective is to uncover how perceived uncertainty and savings adequacy affect current savings decisions. Hence, observing only past behavior, such as accumulated retirement wealth or an individual's savings rate in a pension plan, would not reveal these effects because current levels of perceived uncertainty and savings adequacy are the result and not the cause of past saving behavior.

\subsubsection{Perceived savings inadequacy}

To measure individuals' perceived savings adequacy, we use a metric to gauge whether individuals perceive their current retirement savings to be adequate to permit them to retire comfortably. In particular, in accordance with Hershey, Henkens, and Van Dalen (2007), we measure perceived savings adequacy using a five-point scale ranging from "totally inadequate" to "totally adequate" to collect responses to the following question: "Based on how you expect to live in retirement and given that you do not adjust your current saving behavior, do you expect to have adequate financial resources to retire comfortably?" We divide the respondents into two groups based on whether they perceive their current saving behavior as adequate (0) or inadequate (1).

Much other research on savings adequacy used objective measures of savings adequacy (e.g., total wealth accumulation, replacement rates, retirement plan contributions). There are at least two important reasons in favor of using a subjective measure for savings adequacy in our study. First, there is no standard retirement adequacy measure against which to measure the observed saving behavior of individuals or households (Scholz et al., 2006: 608). As a consequence, views of savings adequacy for retirement are widely diverging (Skinner, 2007). 
Second, previous research has indicated that subjective variables can have strong effects on financial decision making (e.g., Donkers \& van Soest, 1999).

\subsubsection{Savings adequacy uncertainty}

Savings adequacy uncertainty was measured (after reverse coding) using a seven-point scale ranging from "very certain" to "very uncertain" to collect answers to the following question: "You indicate that you expect to have (inadequate/ adequate) financial resources to live comfortably during retirement. How certain are you that your expectation turns out to be true?"

\subsubsection{Financial constraints}

To account for an individual's financial ability to change his savings level, we use a question which is answered by panel respondents every year. In particular, on a five-point scale ranging from "expenditures will be much higher than income" to "expenditures will be much lower than income", respondents answered the question: "When you think of the NEXT 12 MONTHS, do you think the expenditures of your household will be higher than the income of the household, about the same as the income of the household, or lower than the income of the household?"

\subsubsection{Control variables}

Details regarding the control variables can be found in appendix A. As control variables, we include financial literacy, goal clarity, income knowledge, past information search activities and savings, risk aversion, gender, education, household income, number of children, partner, main wage earner of the household, financial administrator of the household, availability of a pension fund and primary occupation.

\subsection{Sample}

Our model of retirement savings decisions is empirically tested using data collected through a Dutch household panel of CentERdata. This panel is representative of the Dutch population. 
CentERdata collects a vast array of detailed information about an individual's financial, psychological and socio-demographic situation. In addition to this general data collection, supplementary questionnaires can be tailored to collect information regarding specific parameters of interest. Respondents from the panel were selected that were between ages 25 and 65 because these respondents are most likely to be responsible for making retirement savings decisions. We only include respondents that are not yet retired and are not attending college. Our final sample consists of 765 respondents who provided complete information to us.

In our sample, 22 percent of the respondents perceive their current saving behavior as inadequate. Respondents reported a mean score of 3.6 for the level of uncertainty (measured on a scale from 1 to 7) when predicting whether they save adequately or not. In accordance with the reports of other studies (e.g., Choi et al., 2002), our sample also demonstrated low behavioral intentions, with mean values of 2.5 (scale $1-7$ ) and 1.9 (scale $1-5$ ) for an individual's additional savings intention and information search intention, respectively. Table A.2 (appendix A) describes the sample in greater detail.

\subsection{Model}

To elucidate the relationship between perceived savings adequacy, savings adequacy uncertainty, financial constraints and intended retirement saving behavior, we use the ordered logit model, as additional savings intention and information search intention are both measured as ordinal variables with seven and eight ${ }^{2}$ categories, respectively (Greene, 2003: 736). The ordered logit model for a variable with $\mathrm{J}$ ordered categories reads as follows:

$$
\text { Intention* }=X^{\prime} \beta+\varepsilon
$$

\footnotetext{
2 Information search is measured with two questions on a 5-point scale. Because the average score of 4.5 is not present, we have 8 instead of 9 categories.
} 
where

$$
\begin{aligned}
& \text { Intention }=1 \quad \text { if intention } * \alpha_{1} \\
& \text { Intention }=\mathrm{j} \quad \text { if } \alpha_{\mathrm{j}-1}<\text { intention } * \alpha_{\mathrm{j}} \quad \text { for } \mathrm{j}=2, \ldots, \mathrm{J}-1 \\
& \text { Intention }=\mathrm{J} \quad \text { if } \alpha_{\mathrm{J}-1}<\text { intention } *
\end{aligned}
$$

Here intention * represents a latent variable, and $\alpha_{1}$ to $\alpha_{J-1}$ are unobserved thresholds that satisfy $\alpha_{1} \leq \alpha_{2} \leq \ldots \leq \alpha_{J-1} . X$ contains all explanatory variables, and $\varepsilon$ is the error. We mean center our measures of savings adequacy uncertainty and financial constraints to enhance the interpretation of the results, given the presence of interactions. Thus, the signs of the coefficients for these explanatory variables can be interpreted relative to the population mean.

\section{Results}

\subsection{Intention to make retirement savings contributions}

Table 1 presents the estimation results for an individual's additional savings intention. To test our expectations, we estimate a three-way interaction effect model, in which we include our three independent variables of interest. First, we find a positive main effect for the dummy variable of inadequate savings $(\beta=.433 ; p=.020)$. Second, we find a positive main effect of

\begin{tabular}{|c|c|c|c|}
\hline & \multicolumn{3}{|c|}{ Savings intention } \\
\hline & $\mathrm{B}$ & & St. error \\
\hline Inadequate savings & .433 & * & .186 \\
\hline Financially unconstrained & .011 & & .105 \\
\hline Uncertainty & .233 & ** & .069 \\
\hline Inadequate $\mathrm{x}$ uncertainty & -.206 & & .118 \\
\hline Inadequate $\mathrm{x}$ financially unconstrained & .193 & & .221 \\
\hline Financially unconstrained $x$ uncertainty & .192 & * & .078 \\
\hline Inadequate $x$ uncertainty $x$ financially & -.491 & ** & .140 \\
\hline
\end{tabular}
uncertainty $(\beta=.233 ; \mathrm{p}=.001)$. For those with inadequate savings, however, the positive effect Table 1: Estimation results of additional savings intention 


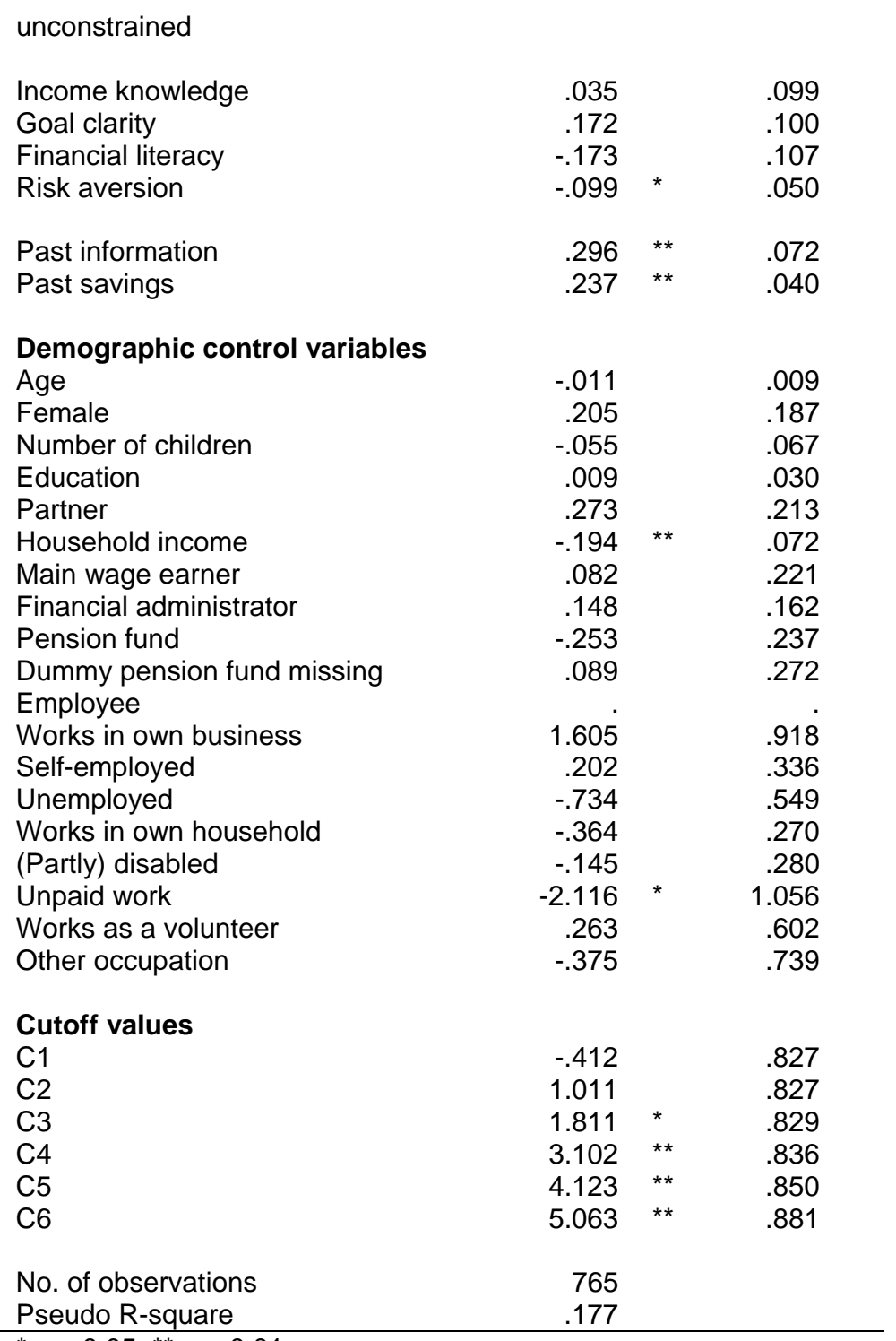

${ }^{\star} p<0.05,{ }^{\star \star} p<0.01$.

of uncertainty vanishes because of its negative interaction effect with inadequate savings $(\beta=$ -

$.206 ; \mathrm{p}=.080)$. Moreover, in line with our expectations, the effect of uncertainty even reverses if individuals are not financially constrained, which is indicated by a significant three-way interaction effect among the variables inadequate savings, savings adequacy uncertainty and financially unconstrained $(\beta=-.491 ; p=.000)$. As is clear from our results, the interactions in our model play an important role. A test on the joint significance of all interactions also supports this $\left(\chi^{2}=11.97\right.$, d.f. $\left.=4, p=.018\right)$. 
Figure 2: The three-way interaction effect for additional savings intention

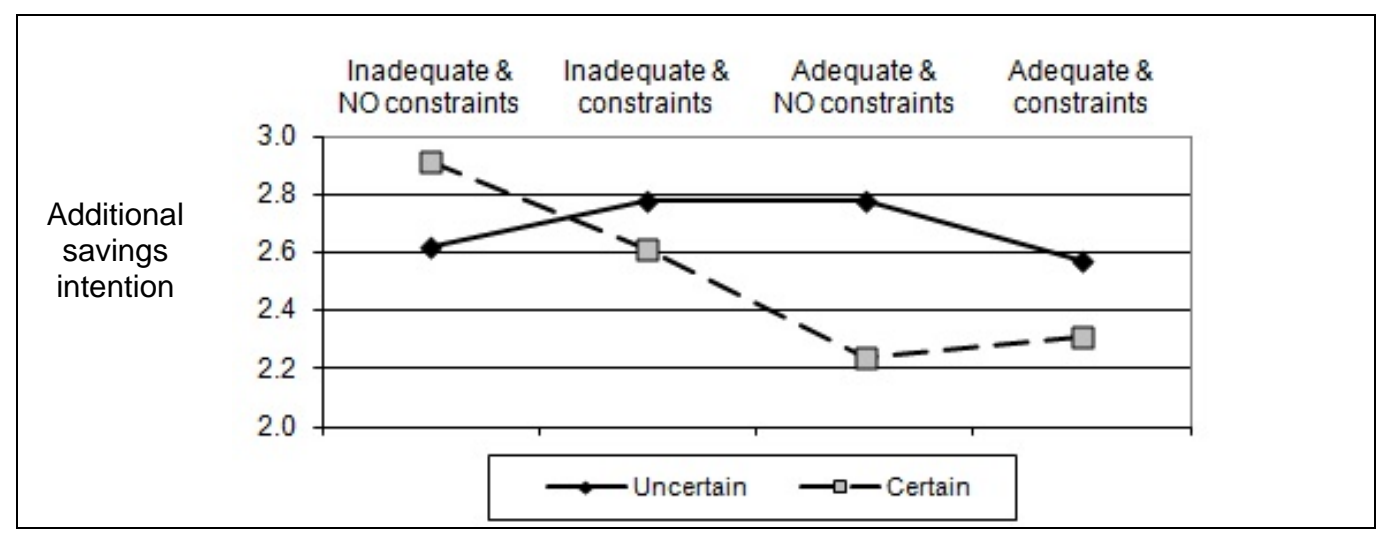

To enhance its interpretation, the three-way interaction effect is graphically illustrated in figure 2. This figure illustrates how our three variables of interest influence the intention to make additional savings contributions in the next 12 months. To do so, we calculate predicted savings intentions, using the estimated logit model, for all combinations of the dummy variable inadequate savings ( 0 vs. 1$)$, the $25^{\text {th }}$ and $75^{\text {th }}$ percentile for uncertainty ( 4 vs. 6$)$, and the same percentiles for financial constraints (3 vs. 4). We hold all other control variables constant at the sample average, and plot the predicted values.

Two findings in this figure are particularly interesting and improve our understanding of the reported three-way interaction effect. First, for those who believe they save adequately, uncertainty has a positive effect on additional savings intention (Intention High vs. Low Uncertainty $=$ 2.78 vs. 2.24 and 2.57 vs. 2.31 for the financially unconstrained and constrained, respectively). This positive effect of uncertainty is in accordance with the economic precautionary saving motive discussed previously. Second, for those who think they save inadequately, uncertainty and financial ability are both important factors in explaining additional savings intentions. Individuals who are certain that they save inadequately and are financially unconstrained have 
the highest intention to save more (Intention Low Uncertainty $=2.91$ ). For this group of individuals, uncertainty has a negative effect on additional savings intentions (Intention High Uncertainty $=2.62$ ). When we contrast the negative effect of uncertainty for those who are not financially constrained with the effect of uncertainty for those who are financially constrained, we find a significant difference $(p=0.010)$; thus, the effect of uncertainty is moderated by financial constraints. This negative impact of uncertainty on savings intentions is consistent with the literature on choice deferral. Overall, these results support our expectation of opposing roles for uncertainty, as its impact depends on perceived savings adequacy and financial constraints.

\subsection{Intention to search for retirement savings information}

In table 2, we present the results of two ordered logit models for individuals' intention to search for retirement savings information. In both models, we use the composite information search intention scale as the dependent variable. The difference between the two models is that we control for additional savings intentions in our second model to demonstrate the effects of our variables on search behavior that is not caused by these intentions. Therefore, in model 1 , the coefficients can be interpreted as overall effects on retirement search behavior, which can be either related or unrelated to intended additional savings contributions. In model 2 , the coefficients can be interpreted as the consequences for search behavior that is unrelated to intended additional savings contributions, i.e., ongoing retirement information search. 
Table 2: Estimation results of information search intention

\begin{tabular}{|c|c|c|c|c|c|c|}
\hline & \multicolumn{3}{|c|}{$\begin{array}{l}\text { Model 1: Overall search } \\
\text { intention }\end{array}$} & \multicolumn{3}{|c|}{$\begin{array}{l}\text { Model 2: Search intention, } \\
\text { separating out additional } \\
\text { savings intention }\end{array}$} \\
\hline & $\mathrm{B}$ & & St. error & $\mathrm{B}$ & & St. error \\
\hline Inadequate savings & .436 & * & .193 & .094 & & .203 \\
\hline Financially unconstrained & -.034 & & .111 & -.127 & & .117 \\
\hline Uncertainty & .319 & ** & .073 & .201 & ** & .078 \\
\hline Inadequate $\mathrm{x}$ uncertainty & -.321 & ** & .124 & -.265 & * & .133 \\
\hline Inadequate $x$ financially unconstrained & -.048 & & .228 & -.160 & & .240 \\
\hline Financially unconstrained $x$ uncertainty & .133 & & .081 & .079 & & .088 \\
\hline $\begin{array}{l}\text { Inadequate } \mathrm{x} \text { uncertainty } \mathrm{x} \text { financially } \\
\text { unconstrained }\end{array}$ & -.385 & ** & .145 & -.213 & & .154 \\
\hline Income knowledge & .185 & & .104 & 216 & & .111 \\
\hline Goal clarity & .309 & ** & .105 & .256 & * & .112 \\
\hline Financial literacy & -.169 & & .113 & -.132 & & .119 \\
\hline Risk aversion & -.098 & & .052 & -.034 & & .056 \\
\hline Past information & .664 & $\star *$ & .077 & .563 & $\star \star$ & .081 \\
\hline Past savings & .053 & & .041 & -.092 & * & .045 \\
\hline Additional savings intention & & & & 1.061 & ** & .065 \\
\hline \multicolumn{7}{|l|}{ Demographic control variables } \\
\hline Age & -.002 & & .009 & .002 & & .010 \\
\hline Female & .057 & & .195 & -.070 & & .205 \\
\hline Number of children & -.171 & * & .071 & -.156 & * & .075 \\
\hline Education & .002 & & .032 & .014 & & .034 \\
\hline Partner & -.017 & & .219 & -.272 & & .230 \\
\hline Household income & -.063 & & .074 & .056 & & .078 \\
\hline Main wage earner & .030 & & .231 & .039 & & .242 \\
\hline Financial administrator & .274 & & .171 & .196 & & .180 \\
\hline Pension fund & 167 & & .256 & .255 & & .271 \\
\hline \multirow{2}{*}{\multicolumn{7}{|c|}{$\begin{array}{l}\text { Employee } \\
\text { Emplis }\end{array}$}} \\
\hline & & & & & & \\
\hline Works in own business & -.544 & & .988 & -1.864 & & 1.062 \\
\hline Self-employed & -.233 & & .358 & -.587 & & .382 \\
\hline Unemployed & -.307 & & .557 & .273 & & .575 \\
\hline Works in own household & -.266 & & .290 & .126 & & .303 \\
\hline (Partly) disabled & -.361 & & .295 & -.286 & & .312 \\
\hline Unpaid work & -1.158 & & 1.064 & -.291 & & 1.198 \\
\hline Works as a volunteer & -1.594 & * & .755 & -2.526 & * & .867 \\
\hline Other occupation & -.433 & & .772 & -.265 & & .811 \\
\hline \multicolumn{7}{|l|}{ Cutoff values } \\
\hline C1 & 1.766 & * & .868 & 4.116 & ** & .934 \\
\hline C2 & 1.913 & * & .868 & 4.304 & ** & .936 \\
\hline C3 & 3.252 & $\star \star$ & .873 & 6.086 & $\star \star$ & .950 \\
\hline C4 & 3.529 & $\star *$ & .875 & 6.467 & ** & .953 \\
\hline C5 & 4.852 & ** & .885 & 8.288 & ** & .974 \\
\hline C6 & 5.174 & $\star \star$ & .889 & 8.727 & $\star \star$ & .980 \\
\hline $\mathrm{C} 7$ & 6.732 & $\star \star$ & .928 & 10.636 & $\star \star$ & 1.031 \\
\hline No. of observations & 765 & & & 765 & & \\
\hline Pseudo R-square & .224 & & & .483 & & \\
\hline
\end{tabular}


Model 1 illustrates the results of overall retirement search behavior. We find results that are very similar to the results that were obtained for additional savings intention. First, we find a significant positive coefficient for the dummy variable of inadequate savings $(\beta=.436 ; \mathrm{p}=$ $.024)$, as well as for uncertainty $(\beta=.319 ; \mathrm{p}=.000)$, which again disappears in situations for which individuals expect to save too little $(\beta=-.321 ; p=.010)$. Second, similarly to additional savings intentions, we find a significant three-way interaction effect for our three variables of interest $(\beta=-.385 ; \mathrm{p}=.008)$.

The fact that the findings for information search intention are similar to those for additional savings intention is also evident from figure 3 , in which we graphically represent the three-way interaction effect. For this representation, we use the same procedure described for additional savings intention. Again, the figure indicates that, for individuals who believe that they save adequately, uncertainty results in a higher intention to search for information (Intention High vs. Low Uncertainty $=2.06$ vs. 1.67 and 1.98 vs. 1.72 , for the financially unconstrained and constrained, respectively). In contrast, for those who think they save inadequately, uncertainty results in a lower intention to search for information, but only if individuals are not financially constrained (Intention High vs. Low Uncertainty $=1.85$ vs. 2.03 ). Thus, for this "inadequate savings" group, uncertainty deters individuals from considering extra information searches, even though they have sufficient financial means. Overall, observing the same impact of uncertainty on information search intention and additional savings intention supports our notion that individuals engage in (purchase-oriented) information search to support additional savings decisions. 
Figure 3: The three-way interaction effect for information search intention

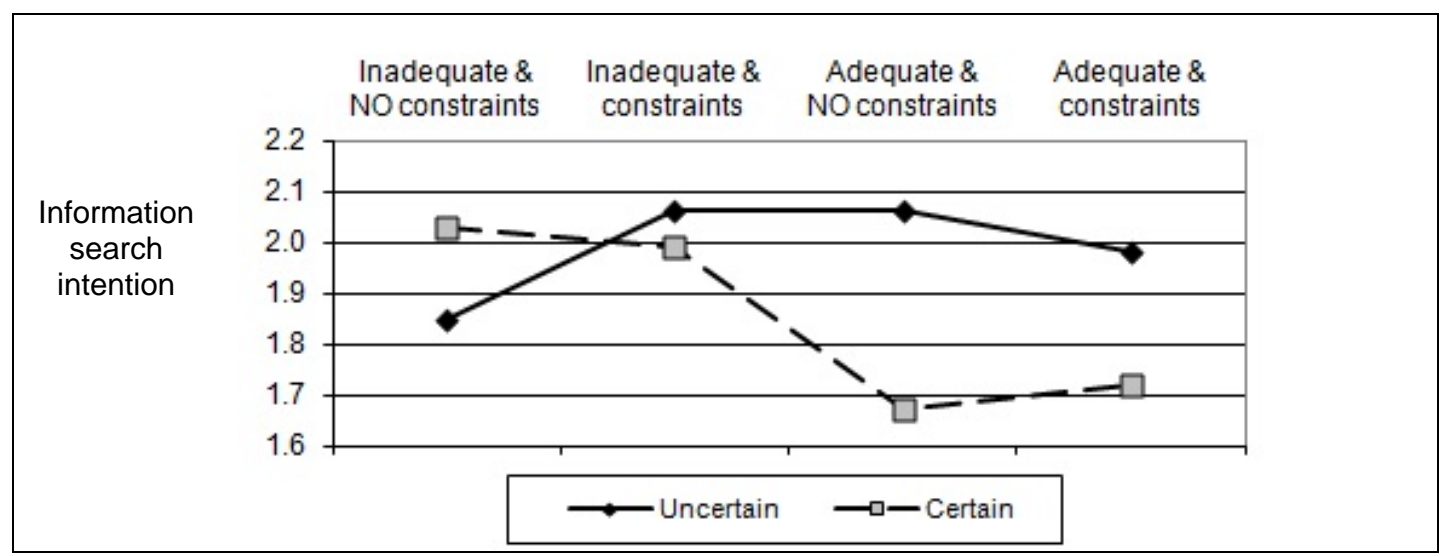

Figure 4: The three-way interaction effect for information search intention after separating out the additional savings intention

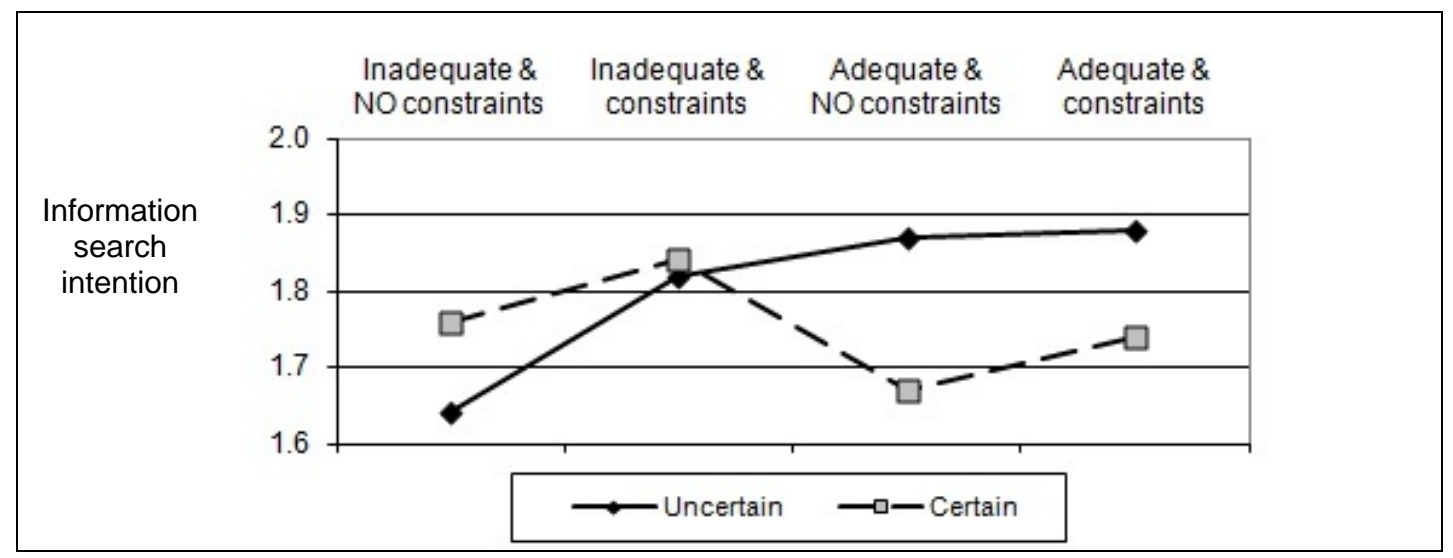

In model 2, we control for additional savings intention to observe whether individuals also use information search to lower uncertainty when additional savings are not directly considered (i.e., ongoing information search). As expected, we find a strong and significant effect of additional savings intention $(\beta=1.061 ; p=.000)$. The main effect of uncertainty is positive $(\beta=$ $.201 ; \mathrm{p}=.010)$, but for those with inadequate savings this effect is fully cancelled by the 
interaction between inadequate savings and uncertainty $(\beta=-.265 ; p=.046)$. Furthermore, we see that the three-way interaction effect becomes insignificant $(\beta=-.213 ; p=.167)$, indicating that financial constraints no longer have a significant effect. A test of the joint significance of the main effect and all interaction terms with financial constraints also supports this $\left(\chi^{2}=4.60\right.$, d.f. $=$ $4, p=.33)$.

In figure 4 we graphically represent this ongoing information search model, which is constructed using the same procedure as before. The figure indicates that individuals who think they save adequately use (ongoing) information search to lower uncertainty (Intention High vs. Low Uncertainty $=1.87$ vs. 1.67 ; and 1.88 vs. 1.74 , for the financially unconstrained and constrained, respectively). By contrast, for those who think they save inadequately, uncertainty does not drive information search. When we compare this figure with figure 3, which depicts overall search, we see that after controlling for additional savings intentions, the group characterized by “inadequate savings, uncertainty, and no financial constraints" demonstrates a particularly low intention to search for information. Two alternative explanations may underlie this finding. First, individuals in this group may be relatively uninvolved in the retirement decision process, and thus may focus on information search only when it is necessary to support an additional savings decision. Individuals in other groups, by contrast, may have a higher level of continuing involvement in retirement decisions, and hence may evince a relatively greater focus on ongoing information search to stay informed about changes in the retirement decision environment (e.g., Bloch et al., 1986). Second, searching for more information might elicit negative emotions because it confronts these individuals with their savings problem. The desire to minimize such negative emotions might therefore be another reason why they do not think about their retirement savings and thus do not search for information (Luce, 1998). According to this argument, 
ongoing information search would evoke more positive emotions for those seeking reassurance that they do indeed save adequately.

Table 3: Determinants of savings adequacy uncertainty

\begin{tabular}{|c|c|c|c|}
\hline & \multicolumn{2}{|l|}{$\mathrm{B}$} & St. error \\
\hline Inadequate savings & -.231 & & .169 \\
\hline Financially unconstrained & -.055 & & .092 \\
\hline Income knowledge & -.813 & ** & .096 \\
\hline Goal clarity & -.378 & $\star *$ & .099 \\
\hline Financial literacy & -.334 & ** & .104 \\
\hline Risk aversion & -.142 & ** & .049 \\
\hline Past information & .016 & & .071 \\
\hline Past savings & .013 & & .038 \\
\hline \multicolumn{4}{|l|}{ Demographic control variables } \\
\hline Age & -.008 & & .009 \\
\hline Female & .103 & & .184 \\
\hline Number of children & .069 & & .066 \\
\hline Education & .016 & & .030 \\
\hline Partner & -.015 & & .208 \\
\hline Household income & .039 & & .069 \\
\hline Main wage earner & .334 & & .218 \\
\hline Financial administrator & .120 & & .159 \\
\hline Pension fund & -.069 & & .234 \\
\hline Dummy pension fund missing & .141 & & .270 \\
\hline Employee & . & & . \\
\hline Works in own business & -1.721 & & .960 \\
\hline Self-employed & -.377 & & .335 \\
\hline Unemployed & .946 & & .520 \\
\hline Works in own household & -.287 & & .264 \\
\hline (Partly) disabled & .252 & & .276 \\
\hline Unpaid work & .005 & & .916 \\
\hline Works as a volunteer & .677 & & .600 \\
\hline Other occupation & .503 & & .701 \\
\hline \multicolumn{4}{|l|}{ Cutoff values } \\
\hline C1 & -8.511 & ** & .848 \\
\hline $\mathrm{C} 2$ & -6.119 & ** & .818 \\
\hline C3 & -4.609 & ** & .806 \\
\hline $\mathrm{C} 4$ & -3.187 & ** & .797 \\
\hline $\mathrm{C} 5$ & -1.852 & * & .795 \\
\hline C6 & -.575 & & .807 \\
\hline No. of observations & 765 & & \\
\hline Pseudo R-square & .325 & & \\
\hline
\end{tabular}

${ }^{*} p<0.05,{ }^{* *} p<0.01$. 


\subsection{Additional analysis: determinants of uncertainty}

An understanding of the factors that determine the level of perceived uncertainty is important for those who are responsible for providing individuals with information to lower that uncertainty. Therefore, as shown in table 3, we conduct another ordinal regression analysis using savings adequacy uncertainty as the dependent variable. We control for the same socio-demographic and individual variables as in the previous analyses, and find that retirement income knowledge, retirement goal clarity, financial literacy, and risk aversion have a significant negative impact on perceived savings adequacy uncertainty. The insignificant influence of past information search behavior might be somewhat surprising. However, once we exclude retirement goal clarity, financial literacy and, in particular, income knowledge, the influence of past information search becomes significantly negative. This suggests that the impact of past information search is mediated by goal clarity, financial literacy and, most importantly, income knowledge. Excluding the same set of variables does not result in a significant effect for past savings, suggesting that these variables do not mediate the impact of past savings practices.

\section{Conclusion and discussion}

\subsection{Conclusions}

This study increases our understanding of individuals' intentions to actively make decisions regarding retirement saving behaviors. In particular, we investigate the role that perceived uncertainty plays in saving for retirement and in searching for retirement savings information. Theories in psychology and in economics provide opposing predictions for the impact of savings adequacy uncertainty on one's intentions to start saving (or to increase one's existing saving 
practices). We develop a conceptual model to describe these multiple roles of uncertainty and use a unique representative dataset to empirically test our model.

Taken as a whole, the results of this study support our notion that uncertainty either increases or decreases an individual's intention to make additional savings contributions, depending on the specific circumstances. In particular, we demonstrate that the effect of uncertainty depends on two important factors, namely, an individual's perceived savings adequacy and that individual's financial constraints. In accordance with the economic literature regarding precautionary saving, we find that uncertainty results in a higher intention to make additional savings contributions for those who think that they save adequately. By contrast, in accordance with choice deferral literature in psychology, we find that uncertainty leads to a lower savings intention for those who think that they save inadequately. This detrimental effect of uncertainty is conditional on an individual's financial ability, as a reduction in uncertainty results in more savings only if an individual has sufficient financial resources to actually adjust his saving behavior. We also examine the effect of uncertainty on information search in more detail. We find that, on the one hand, uncertainty has an indirect effect on information search, as uncertainty affects an individual's intention for additional savings, which induces a need to search for purchase-oriented information. On the other hand, uncertainty also has a direct effect on information search because individuals, particularly those who think they save adequately, engage in ongoing information search to directly cope with uncertainty.

\subsection{Discussion}

The theoretical implications of our research are fourfold. First, we find support for the idea that we can apply well-established findings about the role of uncertainty in the evaluation and choice of (product) alternatives to an investigation of an individual's intentions to make savings 
decisions. Specifically, we find evidence for choice deferral in the context of the decision to make extra retirement savings contributions.

Second, our research extends the insights from studies demonstrating that even though many individuals anticipate they are saving inadequately for their retirement, only a few have the intention to actually increase savings (e.g., Choi et al., 2002). Our results provide an explanation for these findings, as we demonstrate that uncertainty and financial constraints are two significant factors affecting the intention to contribute more to savings for those who are currently saving inadequately.

Third, by considering complementary psychological and economic theories of coping with uncertainty, we find that both theories are useful in explaining the impact of uncertainty on retirement savings decisions. For those who save adequately, precautionary motives explain the positive effect of uncertainty, as individuals start saving more to secure themselves against uncertainty. However, for those who save inadequately, the literature on choice deferral explains the negative effect of uncertainty, as uncertainty makes the benefits of adjusting current savings less salient. This psychological effect of uncertainty complements and emphasizes the value of recent studies that seek to find non-economic explanations for retirement saving tendencies (e.g., Hershey, Jacobs-Lawson, McArdle, \& Hamagami, 2007; Lusardi \& Mitchell, 2007b). These studies recognize that individuals are not always the rational, well-informed agents that are assumed by many economic models of saving.

Fourth, our results complement findings in the precautionary saving literature, which has established that individuals start saving more as a response to uncertainty. Note, however, that in the literature regarding precautionary saving, information search plays a far less prominent role, as individuals are often assumed to have access to all relevant information. This assumes that 
only over time new information will be revealed to the individual regarding economic matters such as job opportunities or stock market performance. By contrast, our results indicate a strong impact of uncertainty on information search. Hence, studying savings as the only consequence of uncertainty might overlook information search as another important behavioral response to uncertainty.

From a managerial perspective, our results provide valuable insights for policy makers and practitioners, who have recently started to introduce new initiatives to make savings decision tasks more transparent. For example, Dutch pension funds are now required to send an annual pension statement (Uniform Pension Statement; UPO in Dutch) to workers who participate in a pension scheme, providing them with information about their estimated pension benefits. Furthermore, many websites have started offering their visitors online retirement calculators to assess how much they should be saving for retirement, as well as online testimonials in which pre-retirees and retired persons share their retirement planning experiences. Policy makers should carefully consider whether such developments make individuals feel more or less uncertain regarding their savings adequacy expectations. Decision aids that help to reduce uncertainty might be especially beneficial for those with inadequate retirement savings and no financial constraints because a decrease in uncertainty provides these individuals with a strong incentive to start saving more. Although this seems a promising avenue to increase retirement savings for these individuals, our results also indicate that this group of individuals is particularly unlikely to actively search for information. Hence, simply making such tools available online will be ineffective as the tools will not be used by this subset of individuals.

Thus far, the focus of most available financial decision aids has been on providing individuals with information about their retirement income through methods such as the Uniform 
Pension Statement. Our results indicate that retirement income knowledge is an important factor in decreasing uncertainty. Policy makers should note, however, that simply providing information about expected benefits via the Uniform Pension Statement is only a first step, as our results indicate that the level of uncertainty is affected by more than simply retirement income knowledge alone. For instance, supplementing retirement income information with information about life after retirement could improve an individual's understanding of current savings adequacy. Financial literacy appears to be another important factor to decrease uncertainty. Recent research, however, has not yet found unequivocal results regarding the best means of supporting individuals in improving their financial knowledge (e.g., Lusardi \& Mitchell, 2007a).

\subsection{Limitations and directions for further research}

Our study poses several interesting avenues for future research. First, a limitation of this study is that we only focus on individuals' intentions to make retirement savings decisions. Although the likelihood that someone will actually make extra savings contributions will be an increasing function of one's intentions, it will also be affected by procrastination. The study of the relative importance of both factors examined here on actual savings remains an intriguing area for further research. Moreover, it would be interesting to know whether procrastination is also related to uncertainty.

Second, being limited by the available data, we could only find four factors that explain the level of savings adequacy uncertainty. More research is needed to investigate other potential determinants. For instance, questions such as whether uncertainty is primarily affected by individual psychological dispositions or by the unpredictable (external) decision environment could be addressed, and investigations could be conducted to determine the extent to which individual feelings of uncertainty can be reduced. It is important to attain a better understanding 
of why individuals perceive uncertainty in determining an adequate level of retirement savings because these reasons will inform the discussion of how to best support those individuals in saving for retirement.

Third, we used data from a Dutch household panel to test our model. As indicated by various researchers, including Hershey, Henkens, and Van Dalen (2007), planning and saving tendencies are heterogeneous across countries, in large part due to differences in pension systems. Workers in the U.S., for example, face much more financial responsibility and uncertainty surrounding future pension payouts than Dutch workers. Therefore, it would be interesting to see if the same results are obtained in other institutional settings.

Finally, our results give rise to additional research that focuses on supporting individuals in their construction of retirement preferences (e.g., Slovic, 1995). In particular, information acceleration has been proposed as a valuable tool to assist individuals in understanding new and unfamiliar consumption situations (Urban et al., 1997). In a typical information acceleration process, individuals are invited to explore a rich virtual (online) environment that consists of many different types of information and information formats to learn more about a future situation. Although information acceleration has thus far mainly been used as a tool to support new product development and marketing testing, it seems a promising approach to also support individuals in understanding their future pension needs and preferences. We believe that information acceleration may help individuals decrease their uncertainty regarding adequate savings levels and thereby induce them to adequately prepare for retirement. 


\section{References}

AFM, Netherlands Authority of the Financial Markets (2011). AFM Consumentenmonitor Najaar 2011 Pensioen (AFM Consumer Monitor Autumn 2011 Pension) (in Dutch).

Ajzen, I. (1991). The Theory of Planned Behavior. Organizational Behavior and Human Decision Processes, 50 (2), 179-211.

Bagozzi, R. P., \& Dabholkar, P. A. (1994). Consumer Recycling Goals and Their Effect on Decisions to Recycle: A Means-End Chain Analysis. Psychology \& Marketing, 11 (4), 313-340.

Beach, L. R., \& Mitchell, T. R. (1987). Image Theory: Principles, Goals and Plans in Decision Making. Acta Psychologica, 66 (3), 201-220.

Beatty, S., \& Smith, S. M. (1987). External Search Effort: An Investigation across Several Product Categories. Journal of Consumer Research, 149 (1), 83-95.

Beshears, J., Choi, J. J., Laibson, D., \& Madrian, B. C. (2008). The Importance of Default Options for Retirement Savings Outcomes: Evidence from the United States. In S. J. Kay, \& T. Sinha (Eds.), Lessons from Pension Reform in the Americas (pp. 59-87). Oxford: Oxford University Press.

Bernheim, B. D., \& Scholz, J. K. (1993). Private Saving and Public Policy. In J. M. Poterba (Ed.), Tax Policy and the Economy, Vol. 7 (pp. 73-110). Cambridge: MIT Press.

Bloch, P. H., Sherrell, D. L., \& Ridgway, N. M. (1986). Consumer Search: An Extended Framework. Journal of Consumer Research, 13 (1), 119-126.

Business Week (2010, July 15). Pension Reform: Europe Wants Later Retirements.

Carroll, C. D., \& Samwick, A. A. (1998). How Important is Precautionary Saving?. The Review of Economics and Statistics, 80 (3), 410-419. 
Carroll, C. D., \& Kimball, M. S. (2008). Precautionary Saving and Precautionary Wealth. In S. N. Durlauf, \& L. E. Blume (Eds.), The New Palgrave Dictionary of Economics, (2nd ed., pp. 579-584). London: Palgrave MacMillan.

Chan, S., \& Stevens, A. H. (2008). What You Don't Know Can’t Help You: Pension Knowledge and Retirement Decision-Making. The Review of Economics and Statistics, 90 (2), 253266.

Choi, J. J., Laibson, D., Madrian, B. C., \& Metrick, A. (2002). Defined Contribution Pensions: Plan Rules, Participant Choices, and the Path of Least Resistance. In J. M. Poterba (Ed.), Tax Policy and the Economy, Volume 16 (pp. 67-114). Cambridge: MIT Press.

Clark, R. L., d'Ambrosio, M. B., McDermed, A. A., \& Sawant, K. (2004). Sex Differences, Financial Education, and Retirement Goals. In O. S. Mitchell \& S. P. Utkus (Eds.), Pension Design and Structure: New Lessons from Behavioral Finance (pp. 185-206). Oxford: Oxford University Press.

Croy, G., Gerrans, P., \& Speelman, C. (2010). The Role and Relevance of Domain Knowledge, Perceptions of Planning Importance, and Risk Tolerance in Predicting Savings Intentions. Journal of Economic Psychology, 31 (6), 860-871.

Davies, J. B. (1981). Uncertain Lifetime, Consumption, and Dissaving in Retirement. The Journal of Political Economy, 89 (3), 561-577.

Dhar, R. (1997). Consumer Preference for a No-Choice Option. Journal of Consumer Research, $24(2), 215-231$.

Donkers, B., \& van Soest, A. (1999). Subjective Measures of Household Preferences and Financial Decisions. Journal of Economic Psychology, 20 (6), 613-642. 
Greene, W. H. (2003). Econometric Analysis (5th ed.). Upper Saddle River, New Jersey: Pearson Education, Inc.

Helman, R., Copeland, C., \& VanDerhei, J. (2010). The 2010 Retirement Confidence Survey: Confidence Stabilizing, But Preparations Continue to Erode. Employee Benefit Research Institute Issue Brief, no. 340 (March).

Hershey, D. A., Walsh, D. A., Brougham, R., Carter, S., \& Farrel, A. (1998). Challenges of Training Pre-Retirees to Make Sound Financial Planning Decisions. Educational Gerontology, 24 (5), 447-470.

Hershey, D. A., Henkens, K., \& van Dalen, H. P. (2007). Mapping the Minds of Retirement Planners: A Cross-Cultural Perspective. Journal of Cross-Cultural Psychology, 38 (3), $361-382$

Hershey, D. A., Jacobs-Lawson, J. M., McArdle, J. J., \& Hamagami, F. (2007). Psychological Foundations of Financial Planning for Retirement. Journal of Adult Development, 14 (12), 26-36.

Howard, J. A., \& Sheth, J. N. (1969). The Theory of Buyer Behavior. New York: Wiley.

Hubbard, R. G., Skinner, J., \& Zeldes, S. P. (1995). Precautionary Saving and Social Insurance. Journal of Political Economy, 103 (2), 360-399.

Iyengar, S. S., Huberman, G., \& Jiang, W. (2004). How Much Choice is Too Much? Contributions to 401(k) Retirement Plans. In O. S. Mitchell \& S. P. Utkus (Eds.), Pension Design and Structure: New Lessons from Behavioral Finance (pp. 83-96). Oxford: Oxford University Press.

Janiszewski, C. (1998). The Influence of Display Characteristics on Visual Exploratory Search Behavior. Journal of Consumer Research, 25 (3), 290-301. 
Lipshitz, R., \& Strauss, O. (1997). Coping with Uncertainty: A Naturalistic Decision-Making Analysis. Organizational Behavior and Human Decision Processes, 69 (2), 149-163.

Luce, M. F. (1998). Choosing to Avoid: Coping with Negatively Emotion-Laden Consumer Decisions. Journal of Consumer Research, 24 (4), 409-433.

Lusardi, A. (1997). Precautionary Saving and Subjective Earnings Variance. Economic Letters, $57(3), 319-326$.

Lusardi, A., \& Mitchell, O. S. (2007a). Financial Literacy and Retirement Preparedness: Evidence and Implications for Financial Education. Business Economics, 42 (1), 35-44.

Lusardi, A., \& Mitchell, O. S. (2007b). Baby Boomer Retirement Security: The Roles of Planning, Financial Literacy, and Housing Wealth. Journal of Monetary Economics, 54 (1), 205-224.

Madrian, B. C., \& Shea, D. F. (2001). The Power of Suggestion: Inertia in 401(k) Participation and Saving Behavior. Quarterly Journal of Economics, 116 (4), 1149-1187.

Moe, W. W. (2003). Buying, Searching, or Browsing: Differentiating Between Online Shoppers Using In-Store Navigational Clickstream. Journal of Consumer Psychology, 13 (1\&2), 29-39.

Moorthy, S., Ratchford, B. T., \& Talukdar, D. (1997). Consumer Information Search Revisited: Theory and Empirical Analysis. Journal of Consumer Research, 23 (4), 263-277.

Osman, M. (2010). Controlling Uncertainty: A Review of Human Behavior in Complex Dynamic Environments. Psychological Bulletin, 136 (1), 65-86.

Palumbo, M. G. (1999). Uncertain Medical Expenses and Precautionary Saving Near the End of the Life Cycle. Review of Economic Studies, 66 (2), 395-421. 
Punj, G. N., \& Staelin, R. (1983). A Model of Consumer Information Search Behavior for New Automobiles. Journal of Consumer Research, 9 (4), 366-380.

Scholz, J. K., Seshadri, A., \& Khitatrakun, S. (2006). Are Americans Saving “Optimally” for Retirement. Journal of Political Economy, 114 (4), 607-643.

Skinner, J. (2007). Are You Sure You're Saving Enough for Retirement?. Journal of Economic Perspectives, 21 (3), 59-80.

Slovic, P. (1995). The Construction of Preference. American Psychologist, 50 (5), 364-371.

Tversky, A., \& Shafir, E. (1992). Choice under Conflict: The Dynamics of Deferred Decision. Psychological Science, 3 (6), 358-361.

Urban, G. L., Hauser, J. R., Qualls, W. J., Weinberg, B. D., Bohlmann, J. D., \& Chicos, R. A. (1997). Information Acceleration: Validation and Lessons from the Field. Journal of Marketing Research, 34 (1), 143-153.

Urbany, J. E., Dickson, P. R., \& Wilkie, W. L. (1989). Buyer Uncertainty and Information Search. Journal of Consumer Research, 16 (2), 208-215.

VanDerhei, J., \& Copeland, C. (2010). The EBRI Retirement Readiness Rating:TM Retirement Income Preparation and Future Prospects. Employee Benefit Research Institute Issue Brief, no. 344 (July).

Van Rooij, M. C. J., Lusardi, A., \& Alessie, R. J. M. (2011). Financial Literacy and Retirement Planning in the Netherlands. Journal of Economic Psychology, 32 (4), 593-608.

Wakslak, C. J., Trope, Y., Liberman, N., \& Alony, R. (2006). Seeing the Forest When Entry Is Unlikely: Probability and the Mental Representation of Events. Journal of Experimental Psychology: General, 135 (4), 641-653. 
Wijzer in Geldzaken, the Money-Wise Guide (2011). Zorgen over het pensioeninkomen (Worries about pension income) (in Dutch). 